\title{
Relationship between Psychoticism and Creativity
}

\author{
Khair Muhammad ${ }^{1}$, Masood Nadeem ${ }^{2}$, Arif Nadeem ${ }^{3}$
}

\begin{abstract}
Historically, creativity has been linked to mad geniuses. Different research studies explored the relationship between personality traits and creativity. Therefore, the aim of this study was to examine that whether there is a relationship between psychoticism and creativity. A cross sectional quantitative research design was employed to recruit online 200 university students from June 2020 to July 2020. Psychoticism sub scale of Eysenck Personality Questionnaire-revised short version (EPQRS) and Kaufman Domains of Creativity Scale (K-DOCS) were introduced to participants after obtaining an informed consent via Google Docx. Data were analyzed by using SPSS v.23. Descriptive statistics, Pearson correlation and independent sample $t$-test were the main statistical tools used in this study. There was found a non-significant negative correlation between psychoticism and creativity. The level of psychoticism and creativity was significantly different in married and non-married participants. Psychoticism is viewed as a risk factor for developing psychosis (especially bipolar disorder and schizophrenia), criminality and psychopathy on negative extreme and linked to creativity on the positive extreme. Therefore, it will be helpful to eliminate the stigmatization attached to psychoticism personality trait by focusing on its positive extreme both for individual and social entities.
\end{abstract}

Key Words: Psychoticism, Creativity, Pearson's Correlation, Independent Sample $t$-test

Received: 12 September 2021; Revised Received: 07 December 2021; Accepted: 30 December 2021

${ }^{1}$ MS Scholar, Department of Psychology, Lahore Garrison University, Lahore, Pakistan.

${ }^{2}$ Professor, Department of Applied Psychology, The Islamia University of Bahawalpur, Pakistan.

${ }^{3}$ Lecturer, Department of Applied Psychology, Government College University, Faisalabad, Pakistan.

\section{Corresponding Author Email:}

khairo.wazir@gmail.com

\section{Introduction}

Psychoticism is one of the personality predisposition defined by Hans J. Eysenck as a continuum that has empathic, conventional, socialized, conformist and altruistic personality traits on one extreme defining low psychoticism and aggressive, impulsive, hostile, schizoid, affective disorder, unipolar depressive, schizophrenic traits on the other extreme defining high psychoticism (Eysenck, 1995). Eysenck argued that psychoticism is a personality trait which is closely linked to creative thought and behavior (Eysenck, 1993). Creativity is the capability of making novel, task appropriate, surprising or useful contributions. According to Hennessey and Amabile (2010), a new product or idea or a solution to a problem which possess some value to the individual or the larger social group is defined as creativity. Eysenck and others also empirically supported the notion that psychoticism and creativity are associated (Batey \& Adrian, 2006; Eysenck, 1993).

The Hans Eysenck's linkage of psychoticism and creativity is supported by the study conducted by Woody and Claridge (1977). They make a use of Wallach-Kogan creativity test. They introduced five tasks from Wallach-Kogan creativity tests to 100

This article is distributed under the terms of the Creative Commons Attribution Non Commercial 4.0 License (http://www.creativecommons.org/licenses/by-nc/4.0/) which permits nonCommercial use, reproduction and distribution of the work without further permission provided the original work is attributed as specified. 
oxford students. The researchers found a correlation of $0.32-0.45$ between psychoticism scale with the total number of responses produced and to a correlation of 0.61 to 0.68 to a number of unique responses (Woody \& Claridge, 1977). Subsequently, the study conducted by Woody and Claridge was also replicated by Rawlings (1985). He also found a correlation of 0.20 magnitude between psychoticism and creativity and these results were dependent on testing condition and sample size (Rushton, 1990). Similarly, other studies conducted on subclinical mild populations which consists of individuals having traits of psychoticism or schizotypal found that participants having a psychoticism or schizotypal traits to a higher degree were consistently showing better performance on some creativity's measure (Acar \& Sen, 2013). On the other hand, Martindale (1989) also supported the notion of Hans. J Eysenck about psychoticism and creativity relationship by arguing that this relationship explains swings of physiological arousal in people. A positive relationship between psychoticism and creativity was observed in both students and general population (Abraham et al., 2005). This notion is also supported by the meta-analytic studies which reveals an overall small significant effect across 32 studies between the psychoticism construct and creativity (Runco \& Acar, 2012). According to some studies, there is a strong positive relationship between psychoticism and creativity while others studies reported no relationship between psychoticism and creativity (Batey \& Furnham, 2006). Batey and Furnham (2006) argued that such types of inconsistent results between the two variables are partly due to the fact that Eysenck personality dimensions are contributing to the different domains of creativity and as psychoticism is also made up of different components like schizotypy and latent inhibition (Batey \& Furnham, 2008). According to
Csikszentmihalyi (1993), the psychoticism personality trait does not convey much about creativity and there is a weak relationship between the two variables.

Based on the above mixed findings regarding the relationship between psychoticism and creativity, this research study has the following objectives.

$>$ To examine that whether there is a relationship between psychoticism and creativity.

$>$ To assess that whether psychoticism personality trait and creativity significantly varies among married and non-married participants.

\section{Method}

The quantitative cross-sectional research design was used to recruit 200 participants including both male and female university students via a convenient sampling technique. Currently enrolled male and female university students were recruited for this study. School and college students and pass out students of university were not recruited for this study. The participants recruited for this study had a mean age $(M=$ 21.77, $S D=2.59$ ). After obtaining informed consent from participants, the Psychoticism sub-scale of Eysenck Personality Questionnaire-Revised (EPQ-R) and Kaufman Domains of Creativity Scale (KDOCS) were introduced to participants. The psychoticism sub-scale is comprised of 12 items in which the participants rate themselves on a two-choice format as Yes or No. The item rated as yes is scored as 1 and 0 upon rating as No. The items are scored by simply summing up all the responses by reverse scoring the following items: $1,2,5$, 7, 8, 10, and 12. The higher score on EPQ-R psychoticism sub-scale indicates more psychoticism personality traits (Eysenck et al., 1985). The reliability index of the Eysenck personality questionnaire revised short scale psychoticism dimension is .29 for this study. The Kaufman Domains of 
creativity scale is comprised of 50 items in which the participant has to respond on a 5point Likert format. The Kaufman domains of creativity scale are comprised of 5 domains which include everyday creativity, scholarly creativity, scientific creativity, performance creativity, and artistic creativity. The scoring of scale is, to sum up, all the responses and find out a mean score (Kaufman, 2012). The reliability index of KDOCS for this study is .93. Statistical analysis was carried out via SPSS v.23. Descriptive statistics was carried out to obtain the general picture of the data. A
Pearson's correlation was used to examine the relationship between psychoticism and creativity. An independent sample $t$-test was used to see the mean difference of psychoticism and creativity between married and non-married students. All participants were recruited after obtaining an informed consent. Their privacy and confidentiality of information was strictly maintained. All the participants were aware of their rights to withdrawal from a study at any stage. There was not any type of physical, psychological, and social harm to participants.

\section{Results}

\section{Table 1}

Descriptive Statistics of Participants' Age, Psychoticism and Creativity $(n=200)$

\begin{tabular}{|c|c|c|c|c|}
\hline Variables & $M$ & $S D$ & $n$ & $\%$ \\
\hline Age & 21.67 & 2.46 & & \\
\hline \multicolumn{5}{|l|}{ Gender } \\
\hline Male & & & 107 & 53.5 \\
\hline Female & & & 93 & 46.5 \\
\hline \multicolumn{5}{|l|}{ Education } \\
\hline Undergraduate & & & 182 & 91.0 \\
\hline Graduate & & & 12 & 6.0 \\
\hline Postgraduate & & & 6 & 3.0 \\
\hline \multicolumn{5}{|l|}{ Marital status } \\
\hline Married & & & 12 & 6.0 \\
\hline Unmarried & & & 188 & 94.0 \\
\hline \multicolumn{5}{|l|}{ Socioeconomic status } \\
\hline Upper & & & 56 & 28 \\
\hline Middle & & & 131 & 65.5 \\
\hline Lower & & & 13 & 6.5 \\
\hline \multicolumn{5}{|l|}{ Residence } \\
\hline Rural & & & 82 & 41.0 \\
\hline Urban & & & 118 & 59.0 \\
\hline
\end{tabular}

The descriptive statistics table gives summary of data of 200 participants about participant's age, psychoticism and creativity. The mean age of participants is $M=21.67$ with a $S D=2.46$. There was $53.5 \%$ male, $46.5 \%$ female, $91.0 \%$ undergraduate, $6.0 \%$ graduate, $3.0 \%$ postgraduate, $6.0 \%$ married, $94.0 \%$ unmarried, $28 \%$ upper class, $65.5 \%$ middle class, $6.5 \%$ lower class, $41.0 \%$ rural and $59.0 \%$ urban students. 
Table 2

Pearson's Correlations of Psychoticism and Creativity $(n=200)$

\begin{tabular}{lllll}
\hline Variables & $\boldsymbol{M}$ & $\boldsymbol{S D}$ & $\mathbf{1}$ & $\mathbf{2}$ \\
\hline 1.Psychoticism & 3.85 & 1.64 & - & \\
2.Creativity & 3.16 & 0.59 & -.01 & - \\
\hline
\end{tabular}

$* p<0.05$

$* * p<0.01$

Table 2 gives the Pearson's correlation between psychoticism and creativity in participating students. There was found a statistically non-significant negative relationship between psychoticism and creativity $(r(198)=-0.1, p>0.05)$.

Table 3

Independent Sample t-test for Marital Status Difference in Psychoticism and Creativity ( $n=200)$

\begin{tabular}{llllllll}
\hline Variables & \multicolumn{2}{c}{ Married } & \multicolumn{2}{c}{ Non-married } & \multicolumn{1}{c}{} \\
\cline { 2 - 5 } & $\boldsymbol{M}$ & $\boldsymbol{S D}$ & $\boldsymbol{M}$ & $\boldsymbol{S D}$ & $\boldsymbol{t}(\boldsymbol{d} \boldsymbol{f})$ & $\boldsymbol{p}$ & Cohen's $\boldsymbol{D}$ \\
\hline Psychoticism & 12.66 & 2.18 & 11.14 & 2.68 & $-2.30(13.34)$ & .03 & 0.62 \\
Creativity & 171.58 & 20.62 & 157.38 & 30.72 & $-2.22(14.53)$ & .04 & 0.54 \\
\hline
\end{tabular}

Note. $N=200, M=$ mean, $S D=$ Standard deviation

$\mathrm{n}^{\mathrm{a}}=12, \mathrm{n}^{\mathrm{b}}=188$

$* p<0.05, * * p<0.01$

An independent sample $t$-test indicated that there were significant differences in the scores of psychoticism between married $(M=12.66, \quad S D=2.18)$ and non-married $(M=11.14, S D=2.68), t(13.34)=-2.30$,

\section{Discussion}

The purpose of this research is to examine the association between personality trait like psychoticism and creativity. According to this research findings, there is a negative relationship between psychoticism and creativity. The findings of this study are contradicted with the findings of the study conducted in the past such as the study conducted by Woody and Claridge who finds out that there is positive association between psychoticism and creativity. This study finding also contradicts the findings of replication study conducted by Rowling who also supported the results founded by Woody and Claridge (Woody \& Claridge, 1977). This research findings are also contradicted with the theoretical concept of Hans.J. $p<.05)$. Similarly, there was significant differences in the scores of creativities between married $(M=171.58, S D=20.62)$ and non-married $\quad(M=157.38, \quad S D=30.72), \quad t$ $(14.53)=-2.22, p<.05)$.

Eysenck, according to whom there is a relationship between psychoticism and creativity (Eysenck, 1993). Such types of inconsistencies of this research findings may be due to the following possible explanations. First, the perceptions regarding creativity may be quite different from the actual ability a person possess. The studies regarding creative metacognition reveals the findings that most of the individuals have not selfinsight into their own creativity (ReiterPalmon et al., 2012). People may rate themselves as highly creative because they have an inflated or high level of self-esteem (Goncalo et al., 2010). The other possible explanation may be the validation of Kaufman domains factor across cultures because in most western cultures, 
imagination, humor, unconventionality, freedom and inquisitiveness are emphasized (Murdock \& Ganim, 1993) as compared to eastern cultures where the main emphasis is on morality, contributions in society and the associations of old and new knowledge (Niu \& Sternberg, 2002). Different patterns may result from such comparable preferences and beliefs in different cultures (Cheung \& Yue, 2007). Beside this, the Eysenck Personality questionnaire-revised short form has a low chronbach alpha value of $0.33-0.52$ in a study conducted by Francis et al. (1992) unlike other domains of Eysenck personality predispositions. The final possible explanation may be the mediating role of latent inhibition in the relationship between psychoticism and creativity which is not tested empirically in this research study. Hans Eysenck suggested that psychoticism is related to the phenomenon of latent inhibition (Eysenck, 1995). Therefore, the inconsistencies between the result of this research study and others may be due to all the above mentioned explanations.

This study also found that there was significant mean differences in level of psychoticism personality trait and creativity in married and non-married participants. According to the best of our knowledge, this study is the first study which is examining the psychoticism and creativity in married and non-married students.

\section{Limitations of this Study}

The primary limitation of this study was its online recruitment of participants due to COVID-19 outbreak. Such type of recruitments may have limitations in itself like faking of participants, poor understanding of the scale items and response sets.

\section{Future Recommendations}

The study in future regarding psychoticism and creativity will be more effective if the researchers change the data collection method from online to physical. Second, the future researchers may replicate this study by using a psychoticism scale having good reliability index. As creativity potential is measured by K-DOCS scale used in this study, the future studies may use a creativity scale which measures creativity in terms of products rather in terms of creativity potential. In case of using K-DOCS, it will be better for a future researcher to recruit participants which are more related to the type of domains measured by this scale.

\section{Conflict of Interest}

The authors declared no conflict of interest.

\section{Source of Funding}

The authors stated no source of funding.

\section{References}

Abraham, A., Windmann, S., Daum, I., \& Gunturkun, O. (2005). Conceptual expansion and creative imagery as a function of psychoticism. Consciousness and Cognition, 14, 520-534.

Acar, S., \& Sen, S. (2013). A multilevel meta-analysis of the relationship between creativity and schizotypy. Psychology of Aesthetics, Creativity, and the Arts, 7(3), 214228. https://doi.org/10.1037/a003197 5

Batey, M., \& Adrian, F. (2006). Creativity, intelligence, and personality: A critical review of the scattered literature. Genetic, social, and general psychology monographs, 132, 355- 429. https://doi.org/10.3200/MONO.132. 4.355-430

Batey, M., \& Furnham, A. (2006). Creativity, intelligence, and personality: A critical review of the scattered literature. Genetic, Social, and General Psychology Monographs, 132(4), 355- 
429. https://doi.org/10.3200/MONO. 132.4.355-430

Batey, M., \& Furnham, A. (2008). The relationship between measures of creativity and schizotypy. Personality and Individual Differences, 45(8), 816821. https://doi.org/10.1016/j.paid.20 08.08.014

Cheung, C. K., \& Yue, X. D. (2007). Which Chinese creators are famous and why: Views from Hong Kong and Mainland Chinese students. The Journal of Creative Behavior, 41(3), 177-196.

Csikszentmihalyi, M. (1993). The Evolving self: A Psychology for the Third Millennium. New York: HarperCollins.

Eysenck, H. (1993). Creativity and personality: Suggestions for a theory. Psychological inquiry. 4, 147178.

https://doi.org/10.1207/s15327965pli 0403_1

Eysenck, H. (1995). Genius: The natural history of creativity. New York: Cambridge University.

Eysenck, S. B. G., Eysenck, H. J., \& Barrett, P. (1985). A revised version of the psychoticism scale, Personality and Individual Differences, 6, 21-29.

Francis, L. J., Brown, L. B., \& Philipchalk, R. (1992). The development of an abbreviated form of the Revised Eysenck Personality Questionnaire (EPQR-A): Its use among students in England, Canada, the USA and Australia. Personality and Individual Differences, $\quad 13, \quad 443$ 449.https://doi.org/10.1016/01918869(92)90073-X

Goncalo, J., Flynn, F. J., \& Kim, S. (2010). Are two narcissists better than one? The link between narcissism, perceived creativity, and creative performance. Personality and Social Psychology Bulletin, 36, 1484-1495. https://doi.org/10.1177/01461672103 85109

Hennessey, B.A., \& Amabile, T.M. (2010). Creativity. Annual Review of Psychology, 61, 569- 598.

https://doi.org/10.1146/annurev.psyc h.093008.100416

Kaufman, J. C. (2012). Counting the muses: development of the Kaufman domains of creativity scale (KDOCS). Psychology of Aesthetics, Creativity, and the Arts, 6(4), 298308.

doi: $10.1037 / \mathrm{a} 0029751$

Martindale, C. (1989). Personality, situation, and creativity. In J. A. Glover, R. R. Ronning, and C. R. Reynolds (Eds.), Handbook of creativity. New York: Plenum.

Murdock, M., \& Ganim, R. (1993). Creativity and humor: Integration and incongruity. Journal of Creative Behavior, 27, , 57-70.

Niu, W., \& Sternberg, R. (2002). Contemporary studies on the concept of creativity: The East and the West. Journal of Creative Behavior, 36, 269-288.

https://doi.org/10.1002/j.21626057.2002.tb01069.x

Rawlings, D. (1985). Psychoticism, creativity and dichotic shadowing. Personality and Individual Differences, 6, 737-742.

Reiter-Palmon, R., Robinson-Morral, E., Kaufman, J., \& Santo, J. (2012). Evaluation of self- perceptions of creativity: Is it a useful criterion? Creativity Research Journal, 24, 107114.https://doi.org/10.1080/1040041 9.2012.676980

Runco, M. A., \& Acar, S. (2012). Divergent thinking as an indicator of creative potential. Creativity Research 
Journal, 24(1), 6675. https://doi.org/10.1080/10400419 .2012 .652929

Rushton, J. (1990 ). Creativity, intelligence, and psychoticism. Personality and Individual Differences 11, 12911298. https://doi.org/10.1016/01918869(90)90156-L
Woody, E., \& Claridge, G. (1977). Psychoticism and thinking. British Journal of Social and Clinical Psychology, 241248. https://doi.org/10.1111/j.20448260.1977.tb00225.x 